\title{
Perspectives on socio-cultural context of adolescent reproductive health behaviour in Nigeria
}

\author{
Peter Olasupo Ogunjuyigbe ${ }^{1}$ \\ Department of Demography and Social Statistics, Obafemi Awolowo University, Ile-Ife, Nigeria \\ pogunjuyigbe@yahoo.com \\ Adunola Adepoju \\ Department of Arts and Social Sciences Education, Faculty of Education \\ University of Lagos, Lagos, Nigeria \\ adunadep@yahoo.com
}

\begin{abstract}
This paper utilizes data collected using structured questionnaire, focus group discussion, Rapid Participatory Assessment (RPA) and in-depth interview with stakeholders to obtain information from adolescents on the context of their behaviour at family level, work place, school, the society. The aim was to appraise the changes in the socio-cultural context of adolescent sexual and reproductive health. The study which was carried out among 3, I4I adolescents selected from the state capital, one medium-sized town and two villages in three Nigerian states indicates that: (i) premarital sexual behaviour has become more common over time, as Nigerian society has undergone marked social change (ii) most parents do not talk with their adolescent children about family life issues such as sex, pregnancy and contraception mainly because of cultural beliefs. Increasingly, religion and its insistence on chastity is now a dominant factor in adolescent sexual and reproductive health matters.
\end{abstract}

Keywords: Reproductive, adolescent, knowledge, culture, prevalence

\section{Resume}

Cet article utilise les données recueillies à l'aide questionnaire structuré , discussion de groupes de discussion , l'évaluation participative rapide (RPA) et une entrevue en profondeur avec les intervenants pour obtenir des informations auprès des adolescents sur le contexte de leur comportement au niveau de la famille, lieu de travail , l'école, la société . L'objectif était d' évaluer les changements dans le contexte socio- culturel de la santé sexuelle et reproductive des adolescents .. L'étude qui a été menée auprès de 3.14 I adolescents sélectionnés dans la capitale de l'État, une ville de taille moyenne et deux villages dans trois Etats du Nigeria indique que : ( i) le comportement sexuel avant le mariage est devenu plus fréquent au fil du temps, comme la société nigériane a subi marqué sociale changement (ii) la plupart des parents ne parlent pas avec leurs enfants adolescents sur les questions de la vie familiale, comme le sexe, la grossesse et la contraception principalement en raison de croyances culturelles. De plus en plus, la religion et son insistance sur la chasteté est maintenant un facteur dominant en matière de santé sexuelle et reproductive des adolescents .

Mots clés: la reproduction, de l'adolescent , la connaissance, la culture , la prévalence

\section{Introduction}

The process of modernization and urbanization is changing the traditional values and social practices. Adolescent sexuality and reproductive behaviour have been influenced by religion, mass media and globalization. Changing family structures also imply that young people's personal freedom is subject to fewer community and family pressure, while traditional sex education practices are being abandoned with no other functional system to replace them, forcing cherished traditional values and social practices including premarital sexual norms to undergo changes in unpredictable directions. The change in the norms may be a consequence of general loosening of family control over the behaviour of young men and women, particularly pronounced when young adults are more educated than their parents and other family members (Feyisetan and Pebley, 1989), when they live outside of family households or compounds, and when they live in less traditional settings, in peri-urban, urban and metropolitan centres.

Increasingly, parents are witnessing incidence of their daughter having sexual relations with their prospective husbands before the consummation of mar-

I. Correspondence: P.O. Ogunjuyigbe, Department of Demography and Social Statistics, Obafemi Awolowo University, Ile-Ife.Email: pogunjuyigbe@yahoo.com 
riage. The emphasis on the desirability of pregnancy before marriage has intensified incidents of premarital pregnancy as proof of the woman's capacity to bear children (Alo and Akinde, 20I0).

The Yoruba society attached great importance to female virginity at the time of marriage and every new bride was expected to be a virgin at the time of consummation of marriage, which was usually the first night the new couple slept together as husband and wife (Akanle, 2007). While a virgin bride was a source of pride to her family and was treated with respect and admiration, an 'incomplete bride' (that is, a new bride found to have lost her virginity before marriage) suffered considerable approbation (Feyisetan and Pebley, 1989; Bolaji, 1984). In the traditional lgbo society as well, virginity of the bride was taken for granted, as evident in the local saying that "a woman never forsakes the man who breaks her virginity" (Uchendu, 1965). The Igbo custom that compelled a new bride to divulge, before an idol and in the presence of her husband's family, the name of the person(s) with whom she had been intimate since the day of her bethrothal, helps to forestall premarital sexual relations, especially with any man other than her future husband.

Sexual behaviour of adolescents can largely be attributed to the physiological changes that occur during adolescence. At puberty, they are more conscious of their physical features and may seek sexual gratification as a proof of maturity and lack of factual knowledge of reproductive biology. The average adolescent, though physically and sexually mature, is far from being well informed about human sexuality, and his/her first contact with the subject is either through novels, films, mass media, magazines, or peer group. Majority of parents and teachers have over the years developed 'cold feet' toward the dissemination of sex information in schools or at home and have thereby shielded many adolescents from credible information (Adepoju, 2005; Isiugo-Abanihe and Isiugo-Abanihe, 2007).

However, with the collapse of traditional systems of preparation for adult sexual life, many cultures are changing established values about sexual behaviour. Also, in many parts of Nigeria today, especially in Southern part, better nutrition helps to diminish the age of puberty while increased age at marriage without use of contraceptives exposes female adolescents to the risk of unintended pregnancy and illegal abortion for a longer period. Premarital virginity once held as a prime social norm is now viewed as "socially backward" and "anti-social" and expectations about virginity has eroded (Alo and Akinde, 2010). Emphasis on premarital chastity has also diminished among many ethnic groups. Westernization has made the emphasis on virginity an ideal rather than a reality among the lgbo in the face of long period of schooling, increasing divorce rate and the demise of traditional virginity 'test' (Uchendu, 1965).

The emergence of 'sugar daddies/aristos' and 'sugar mummies' in some parts of the country is associated with high premarital sexual relations among adolescents. "Sugar daddies' and "Sugar mummies" or "ATMs" as they are now generally called, use their wealth and influence in the society to attract young girls and boys for companionship and sexual relations. Schoolgirls may enter into sexual relationships with older men in the hope of securing financial assistance with school-related expenses or the purchase of material goods. The increasing number of street children, gangsters, cultism in schools and drug use are manifestations of poverty and collapse of the social system.

Religion impacts on many areas of adolescent well-being and is an important factor in adolescent sexuality. Religiosity is often positively associated with social values and behaviour, and negatively related to premature sexual involvement and delinquency (Mitike et al., 2008). It also has a profound impact on individual behaviour, even in the face of modernization and its consequences on cultural practices. The implications of all these for adolescents' wellbeing and overall national development cannot be overemphasised, hence, this study sought to appraise the attitude of Nigerian youth to changes in the socio-cultural context of adolescents' sexual and reproductive health behaviour.

\section{The problem}

Major adolescent reproductive health problems in Nigeria include teenage pregnancy; sexually transmitted infections (STIs); illegal abortion which constitute the major cause of deaths among adolescents; high and early entry of adolescents into sexual activity, and lack of adequate information about safe sex (Adepoju, Ogunjuyigbe and Adepoju, 2006; Adeokun, Ricketts, Ajuwon and Ladipo, 2009; UNFPA, 2003). The median age at first marriage nationally is low at 17.9 years ( 14.6 years in Northwest and 20.2 years in Southwest Nigeria). Twice as many adolescent girls as boys (16.2 and 8.5 percent, respectively) have had sex by age 15. As indicated by findings from National AIDS and Reproductive Health Survey, the median age of sexual debut among female adolescents is 17 years (NPC and ORC Macro, 2004, 2009). Adolescent pregnancy of 22 per cent is sustained, in part because 25 percent of the girls are married before 15 years. The incidence of teenage pregnancy and childbearing, however, registered a decline from 28 percent in 1990 to 
22 percent in 1999. Lack of awareness and knowledge by adolescents of their reproductive health issues leads to their poor sexual and reproductive health status and outcomes. This in the main derives from cultural barriers to access credible sources of information. Population and family life education, including sexuality education, is not taught in most secondary schools despite the fact that relevant curricula have been designed and approved (Adepoju, 200 I; Esere, 2008). Various stakeholders withhold reproductive health and sexuality information from adolescents quoting socio-cultural taboos, thereby shielding off adolescents from relevant reproductive health services. It is not gainsaying that in this era of technological advancement, the adolescents are open to alternate routes of information which most of the time negate socio-cultural belief systems and adversely affect the adolescents' sexual wellbeing. There is a need therefore, to create awareness about the implications of the foregone for adolescents' perception of the role of their socio-cultural environment in shaping their attitude towards sexual health and wellbeing. The significance lies on the premise that stakeholders will be able to come up with adolescent friendly measures and programmes that will positively enhance adolescents' attitudes towards their reproductive and sexual health.

\section{Theoretical perspective}

Atwater (1992) in Berger (1999) theorized that, the experience of adolescence is heavily influenced by one's social and cultural environment. Every society whether simple or complex, has its own system for training and educating its youth with much emphasis on education for good life. This view is also held by Meekers (1994) who professed that, societies use sets of norms and values that shape the behaviour of its members. Thus, the incidence of sexual activity before marriage provides an indication of the extent of erosion in traditional values (Miangotar and LeGrand, 20I2).

In many Nigerian societies, the cultural ideology in favour of early marriage is primarily to sustain female virginity and ensure that sexual activity and childbearing take place within marriage (Akanle, 2007). Okore (1987) contends that in the traditional lgbo society, the main reason girls marry early is that as they advance towards puberty, parents are keen to ensure early marriage for their daughters to avoid the embarrassment of premarital pregnancies.

\section{Review of the literature}

The social context plays an important role in determining the pattern of adolescent sexual behaviour and decision-making. Differences in family type, reli- gion, education and peer group are factors that influence the sexuality and reproductive behaviour of adolescents (James and Isiugo-Abanihe, 2010). Social factors that motivate the youth to sexual activity include poverty, peer and social pressure, media, type of residence, cultural values, and so on.

Adolescent pregnancies are now pervasive in societies which had strong traditional prescriptions against premarital childbearing. Age at marriage has increased in Nigeria, just as the incidence of baby mothers, abandoned babies and deaths among pregnant adolescents through illegal abortions. Yet, population policies and programmes still frown at providing contraceptive information and supplies to young people. Adolescent girls, married or unmarried in both rural and urban areas, but more evident in the towns where social controls on the youths have weakened considerably, contribute the greatest proportion of gynecological emergencies (WHO/ UNFPA, 2006). At delivery they suffer from medical complications including anemia, premature delivery, prolonged labour, cervical trauma, even death.

Evidence from literature indicates that unprotected premarital sex is prevalent in Nigeria and the use of contraceptives among adolescents is very low; they also lack knowledge about contraceptives and disease prevention (Walker, 20I2). Generally, a small proportion of the adolescents interviewed claimed knowledge of most of the contraceptive methods, in spite of the fact that majority of adolescent boys and girls had their first sexual experience between ages 13 and 17 years.

Traditionally and most especially in rural communities, a high premium is placed on virginity for unmarried women. A woman who remained so until her wedding day is praised; offered virginity payment and attracts a higher bride price. Those who fail the test are humiliated and ordered to repay the bride price. Therefore, to ensure that girls remained virgin and to save the family from ridicule, many rural dwellers would probably support the practice of early marriage (Nugent, 2006; WHO, 20II). This attitude probably influences the perceptions of adolescents about the issue of marriage. Irrespective of residence (urban or rural) the adolescent boys and girls popularly favor girls marrying after age 18.

Since economic opportunities are scarce and restricted, particularly for girls, adolescents may equate sex and economic survival. Forced to depend on men, young girls are often exchanging sex for money or other gifts, sometimes with older men who may be infected with HIV.

\section{Data sources}

The data for the study is extracted from the study of 
adolescent sexual and reproductive behaviour and needs in Nigeria, conducted by the Human Resources Development Centre, Lagos, during November to December, 2002. A series of approaches were employed in the study: a questionnaire survey, focus group discussion (FGD), Rapid Participatory Assessment (RPA) and in-depth interview in three States - Ogun State (Southwest), Abia State (Southeast) and Rivers State (South-South) - in Nigeria. Ogun state's projected population of 2.7 million growing annually at 2.8 percent is young with forty-five percent below age 15 years. In Rivers state, ethnically and culturally heterogeneous, with the majority of the people Christians, adolescents constitute 23.4 percent of the state's population of 5.2 million in 2006 (NPC, 2010). Abia state with a population of 2.8 million, 90 percent of whom are Christians, had a median age at first marriage of 18 for women and 25 for men. These States capture most of the complex ethnic, religious, socio-cultural, economic, demographic and geographic dynamics in the country, thus enabling comparative perspectives. Sexual activity among adolescents is also high. Contraceptive use remains low partly due to the deeplyrooted pro-natalist tradition of the people. Teenage pregnancy, unsafe abortion and sexually transmitted infections (STIs) are major reproductive health concerns.

In each state, the capital city, one representative medium sized town and two villages were selected for 1054 in-school and out-of-school adolescent interviews in 2002. For the out-of-school adolescents' survey, 27 were conducted from each village, I 25 from medium sized town and 175 from capital city, a total of 354 per state. The in-school adolescents' survey was built around 4 randomly selected schools in the capital city, 4 in medium sized town and one in each of the two villages to yield a system- atic sample of 100 students per lower secondary school and 60 in higher secondary schools for a total of 700 per state. The I,040 completed forms in Ogun State, I,050 in Rivers State and I,05 I in Abia State were analysed for this study. Returned questionnaires were screened, checked for consistency, edited and analysed using a combination of univariate and bivariate analytical methods (Adepoju, Ogunjuyigbe and Adepoju, 2006).

Twelve adolescents randomly selected on the basis of sex, age, education, religion, ethnicity, family set-up and occupation per location were interviewed for the RPA in each state. Six FGDs per state were conducted - two in the capital city, two in medium sized towns, and one each in selected villages. Sixteen in-depth interviews of key stakeholders were also carried out per state. Information from RPAs, FGDs and in-depth interviews were transcribed and analyzed descriptively and used to explain results of quantitative analysis.

\section{Findings and discussion}

The socio-demographic characteristics of adolescents show that majority were aged 15-19 years. Over half (53 percent) of the adolescents lived in urban areas except Abia state. Only 3.7 percent, mostly out-of-school adolescents were currently married. Out-of-school adolescents also attained some level of education before enrolling in a trade (Table I). Only I.7 percent of the adolescents did not have any education and 46 per cent attained primary school education. On average, males were better educated than females and there are more Christians (97 percent in Abia and Rivers, 57 per cent in Ogun) than Muslims (43 per cent in Ogun, 2 percent in Abia and less than I per cent in Rivers) among adolescents in the three states.

Table I Socio-demographic characteristics of adolescent boys and girls, Ogun, Abia and Rivers states

\begin{tabular}{|c|c|c|c|c|c|c|c|}
\hline \multirow[t]{2}{*}{ Characteristics } & \multicolumn{2}{|l|}{ Ogun } & \multicolumn{2}{|l|}{ Abia } & \multicolumn{3}{|l|}{ Rivers } \\
\hline & $\begin{array}{l}\text { Male } \\
(N=559)\end{array}$ & $\begin{array}{l}\text { Female } \\
(\mathbf{N}=48 \mathrm{I})\end{array}$ & $\begin{array}{l}\text { Male } \\
(N=592)\end{array}$ & $\begin{array}{l}\text { Female } \\
(\mathbf{N}=459)\end{array}$ & $\begin{array}{l}\text { Male } \\
(N=5 \mid 9)\end{array}$ & $\begin{array}{l}\text { Female } \\
(N=53 I)\end{array}$ & $\begin{array}{l}\text { Total } \\
(\mathrm{N}=3 \mid 4 I)\end{array}$ \\
\hline \multicolumn{8}{|l|}{ Age } \\
\hline Under 15 & 24.8 & 26.1 & 29.6 & 33.6 & 26.0 & 28.2 & 27.9 \\
\hline 15 and over & 75.2 & 73.9 & 70.4 & 66.4 & 74.0 & 71.8 & 72.1 \\
\hline \multicolumn{8}{|l|}{ Place of residence } \\
\hline Urban & 78.3 & 77.8 & - & 19.2 & 72.1 & 73.1 & 53.2 \\
\hline Rural & 21.2 & 22.2 & 100.0 & 80.8 & 27.9 & 26.9 & 46.8 \\
\hline \multicolumn{8}{|l|}{ Education } \\
\hline None & 0.7 & 0.2 & 4.6 & 1.3 & 1.3 & 1.5 & 1.7 \\
\hline Primary & 24.8 & 17.1 & 13.2 & 8.7 & 18.7 & 10.8 & 15.1 \\
\hline Secondary & 74.5 & 82.7 & 82.1 & 88.7 & 79.0 & 87.2 & 82.2 \\
\hline Religion & & & & & & & \\
\hline
\end{tabular}




\begin{tabular}{lllllllll} 
Christianity & 55.2 & 58.0 & 95.6 & 97.4 & 96.5 & 97.6 & 83.3 & \\
Islam & 44.1 & 41.5 & 2.2 & 0.4 & 0.4 & 0.7 & 15.0 & 1.7 \\
$\begin{array}{l}\text { Traditional } \\
\text { Marital status }\end{array}$ & 0.7 & 0.4 & 2.2 & 2.2 & 3.1 & 1.7 & & \\
Single & & & & & & & 96.8 \\
Married & 98.3 & 97.6 & 97.8 & 96.5 & 94.0 & 96.3 & 3.2 & 100.0 \\
& 1.7 & 2.4 & 2.2 & 3.5 & 6.0 & 3.7 & 100.0 & 100.0 \\
\hline
\end{tabular}

Knowledge of contraceptives is generally low among adolescents: overall, two in five adolescents claimed knowledge of contraceptives. Significantly, a higher proportion of girls than boys in the three survey states (Abia, Ogun and Rivers) claimed knowledge of contraceptives. Condom is by far the most popular method known, and here again, girls lag far behind boys, condom being overwhelmingly a male method. At a far second place is knowledge of the pill, a female method known to more girls than boys (Table 2a).

Adolescents in the surveyed states are precise about the ideal age of sexual intercourse. Two thirds asserted that the ideal age should be between 13 and 17 years, with 20 percent opting for 18 years and over and 13 per cent suggesting age 12 or below. The mean age at first intercourse of 21 years for all adolescent respondents reflects a slightly higher age for boys than girls in the three states. About three quarters of adolescents in Rivers State suggested age 13-17 as appropriate age of sexual intercourse, compared with, for instance, 60 per cent in Abia and two thirds of their counterparts in Ogun State (Table 2b).

Table 2a Knowledge and practice of contraceptives by adolescent boys and girls

\begin{tabular}{|c|c|c|c|c|c|c|c|}
\hline \multirow[t]{2}{*}{ Characteristics } & \multicolumn{2}{|l|}{ Ogun } & \multicolumn{2}{|l|}{ Abia } & \multicolumn{3}{|l|}{ Rivers } \\
\hline & $\begin{array}{l}\text { Male } \\
(N=559)\end{array}$ & $\begin{array}{l}\text { Female } \\
(N=48 I)\end{array}$ & $\begin{array}{l}\text { Male } \\
(N=592)\end{array}$ & $\begin{array}{l}\text { Female } \\
(N=459)\end{array}$ & $\begin{array}{l}\text { Male } \\
(N=519)\end{array}$ & $\begin{array}{l}\text { Female } \\
(N=53 I)\end{array}$ & $\begin{array}{l}\text { Total } \\
(\mathbf{N}=3|4|)\end{array}$ \\
\hline Know methods & 35.5 & 28.3 & 44.8 & 37.7 & 48.9 & 40.1 & 39.5 \\
\hline \multicolumn{8}{|l|}{ Methods known } \\
\hline Condom & 79.9 & 65.6 & 77.8 & 46.3 & 77.9 & 54.9 & 78.0 \\
\hline Pills & 3.7 & 19.7 & 6.2 & 19.1 & 4.2 & 2.2 & 11.4 \\
\hline Withdrawal & 2.6 & 1.6 & - & - & 1.3 & - & 0.9 \\
\hline IUD & 0.5 & 2.5 & 2.9 & 6.8 & 0.8 & 3.6 & 2.7 \\
\hline $\begin{array}{l}\text { Traditional } \\
\text { method }\end{array}$ & 5.3 & 1.6 & 2.1 & 2.5 & 5.7 & 4.6 & 4.0 \\
\hline Abstinence & 4.5 & 3.3 & 1.2 & 3.1 & 2.1 & 5.1 & 3.0 \\
\hline Total & 100.0 & 100.0 & 100.0 & 100.0 & 100.0 & 100.0 & 100.0 \\
\hline
\end{tabular}

Table 2b Age at first sexual intercourse for boys and girls

\begin{tabular}{|c|c|c|c|c|c|c|c|}
\hline & Ogun & & Abia & & Rivers & & \\
\hline Age of sexual intercourse & $\begin{array}{l}\text { Male } \\
(N=559)\end{array}$ & $\begin{array}{l}\text { Female } \\
(N=48 I)\end{array}$ & $\begin{array}{l}\text { Male } \\
(N=592)\end{array}$ & $\begin{array}{l}\text { Female } \\
(N=459)\end{array}$ & $\begin{array}{l}\text { Male } \\
(N=5 \mid 9)\end{array}$ & $\begin{array}{l}\text { Female } \\
(N=53 I)\end{array}$ & $\begin{array}{l}\text { Total } \\
\mathbf{N}=3141\end{array}$ \\
\hline 12 years & 14.2 & 7.0 & 16.3 & 16.7 & 11.3 & 11.3 & 13.3 \\
\hline $13-17$ years & 66.3 & 67.5 & 56.9 & 61.5 & 72.3 & 76.5 & 66.4 \\
\hline 18 years and above & 19.5 & 25.4 & 26.8 & 21.8 & 16.4 & 12.3 & 20.3 \\
\hline $\begin{array}{l}\text { Mean age at first sexual } \\
\text { intercourse }\end{array}$ & 21.2 & 20.1 & 20.5 & 19.0 & 20.0 & 18.4 & 21.0 \\
\hline
\end{tabular}

Stereotyped sexual norms and peer pressure encourage young males to 'prove' their manhood and enhance their social status by having sex. Generally, adolescent behaviour is governed by what their friends say and do and adolescents generally prefer discussing the subject with their peers or sexual partners. Table $3 a$ shows that about 58 percent of adolescents caved in to pressure from their peers. More than two adolescents in five (43 percent), especially boys, attend social functions together. Female adolescents, being under stricter societal surveillance to uphold moral etiquette are not as 
privileged. About one-third of adolescents read or watch phonographic materials together with their peers. In the three surveyed states, boys are more prone to reading and watching pornographic materi- als than girls, while girls are more inclined to discussing sexual matters with their friends, the exception being Rivers State.

Table 3a Peers' influence on sexual relations by adolescent boys and girls

\begin{tabular}{|c|c|c|c|c|c|c|c|}
\hline \multirow[t]{2}{*}{ Characteristics } & \multicolumn{2}{|c|}{ Ogun state } & \multicolumn{2}{|l|}{ Abia state } & \multicolumn{3}{|c|}{ Rivers state } \\
\hline & $\begin{array}{l}\text { Male } \\
(N=559)\end{array}$ & $\begin{array}{l}\text { Female } \\
(\mathbf{N}=\mathbf{4 8} \mathrm{I})\end{array}$ & $\begin{array}{l}\text { Male } \\
(N=592)\end{array}$ & $\begin{array}{l}\text { Female } \\
(N=459)\end{array}$ & $\begin{array}{l}\text { Male } \\
(N=5 \mid 9)\end{array}$ & $\begin{array}{l}\text { Female } \\
(N=53 I)\end{array}$ & $\begin{array}{l}\text { Total } \\
(N=3|4|)\end{array}$ \\
\hline $\begin{array}{l}\text { Attend social function with } \\
\text { friends? }\end{array}$ & 49.1 & 42.8 & 45.4 & 39.0 & 39.5 & 41.2 & 43.1 \\
\hline $\begin{array}{l}\text { Discuss sexual matters } \\
\text { them? }\end{array}$ & 52.6 & 55.2 & 60.3 & 61.7 & 60.3 & 55.7 & 57.5 \\
\hline $\begin{array}{l}\text { Engage in reading and or } \\
\text { watching naked females? }\end{array}$ & 36.4 & 33.6 & 30.7 & 27.4 & 28.9 & 20.6 & 29.0 \\
\hline
\end{tabular}

Table 3b Discussion of sexual matters by adolescent boys and girls in the survey states

\begin{tabular}{|c|c|c|c|c|c|c|c|}
\hline \multirow[t]{2}{*}{ Characteristics } & \multicolumn{2}{|c|}{ Ogun state } & \multicolumn{2}{|l|}{ Abia state } & \multicolumn{3}{|c|}{ Rivers state } \\
\hline & $\begin{array}{l}\text { Male } \\
(\mathrm{N}=559)\end{array}$ & $\begin{array}{l}\text { Female } \\
(\mathbf{N}=48 \mathrm{I})\end{array}$ & $\begin{array}{l}\text { Male } \\
(\mathrm{N}=592)\end{array}$ & $\begin{array}{l}\text { Female } \\
(N=459)\end{array}$ & $\begin{array}{l}\text { Male } \\
(N=519)\end{array}$ & $\begin{array}{l}\text { Female } \\
(N=53 I)\end{array}$ & $\begin{array}{l}\text { Total } \\
(\mathbf{N}=3|4|)\end{array}$ \\
\hline \multicolumn{8}{|c|}{ Sexual issues discussed with: } \\
\hline None & 53.7 & 33.0 & 57.3 & 34.9 & 68.0 & 48.1 & 59.4 \\
\hline Father & 17.1 & 13.6 & 9.1 & 4.4 & 8.7 & 2.8 & 11.7 \\
\hline Mother & 21.5 & 45.2 & 14.7 & 42.9 & 11.2 & 35.1 & 15.9 \\
\hline Sister & 7.3 & 20.0 & 6.3 & 19.4 & 2.5 & 12.1 & 5.5 \\
\hline Brother & 17.5 & 8.1 & 15.5 & 7.0 & 9.8 & 3.2 & 14.4 \\
\hline \multicolumn{8}{|l|}{ Issues discussed } \\
\hline Body cleaning & 2.9 & 3.0 & 7.7 & 7.6 & 13.0 & 14.0 & 6.9 \\
\hline Menstruation & 0.8 & 7.7 & 3.6 & 12.7 & 7.6 & 15.3 & 3.4 \\
\hline Sexual relationship & 57.1 & 52.9 & 54.1 & 42.2 & 59.5 & 46.4 & 56.6 \\
\hline HIV/AIDS prevention & 9.6 & 7.4 & 15.3 & 8.0 & 5.3 & 2.7 & 10.6 \\
\hline Pregnancy prevention & 7.9 & 7.4 & 3.1 & 9.3 & 3.8 & 6.8 & 5.3 \\
\hline $\begin{array}{l}\text { Relationship with opposite } \\
\text { sex }\end{array}$ & 21.7 & 21.5 & 16.3 & 20.3 & 10.7 & 14.9 & 17.3 \\
\hline \multicolumn{8}{|c|}{ Opinion on sex before marriage } \\
\hline Approved & 25.7 & 15.3 & 27.9 & 18.7 & 35.3 & 22.8 & 24.6 \\
\hline Disapproved & 48.6 & 55.6 & 49.0 & 61.2 & 45.7 & 51.0 & 51.5 \\
\hline Undecided & 25.7 & 29.1 & 23.1 & 20.0 & 19.1 & 26.2 & 23.9 \\
\hline
\end{tabular}

When parents do discuss sexual issues with adolescents, abstinence is the most discussed topic. Adolescents with limited formal education claimed they are often cautioned about the kind of sexual relationship that should exist between them and the opposite sex. As shown in Table 3b, most of them, either in-school or out-of-school, engage in such discussion. A significant proportion of adolescents claim to always discuss reproductive and sexuality issues with their friends, irrespective of their socio-economic standing, a tendency that reflects their independence and peer's influence in place of parental dominance or the influence of siblings. In all cases, they need life-coping skills to enable them cope with the myriad of challenges of adolescence (see Adepoju, 2005). Where they are denied access to adequate information and education on sexuality and related matters, adolescents tend to turn to their peers for 'enlightenment'. Frequently discussed issues are avoidance of sexual intercourse, relationship with opposite sex and HIV/AIDS prevention in that order.

Obstacles to communication on sexuality issues Religion, by exerting a profound effect on people's beliefs, behaviour and practices, has been observed as the dominant inhibiting factor in freely discussing sexuality issues between parents and adolescents. 
During the series of RPAs and FGDs, religion was claimed by more than a third of adolescents with secondary education as a major factor inhibiting their freedom from discussing matters relating to sexuality and sexual issues amongst themselves. A majority of the in-school adolescents confirmed that teachers prevent them from discussing sexuality in school. Parental influence tends to be more intense for younger than older adolescents.

\section{Reproductive health challenges facing adolescents}

Reproductive and sexual health challenges facing adolescents are many and are anchored on the family and the policy environment. Within families, parents often do not provide proper direction to the adolescents and government responses to sexual education are not well focused and often counterproductive. As recounted by adolescents in Rivers State, in the past, parents ensured that daughters remained virgins until marriage, which was also usually early. Parents arranged marriages and girls were not meant to be seen openly with their boyfriends. This has changed because adolescents engage in sexual activities early now and they are also marrying a little later in life.

\section{A girl in Port Harcourt recounts:}

Sexual activities are rampant among boys and girls; they want to have sex before marriage. This is one of the problems of the young people here. Some people send their children to do some housework as laborers. So they have sex early and get into many problems.

Some adolescents are learning lessons from the mistakes of their counterparts, as in this case of a 19year old girl in Ogun State:

There is a girl I know that became pregnant while in school. The girl has totally lost her education; she has become a mother too early. Also the young man who impregnated her denied her and her parents abandoned her. She doesn't have money to bring up this child. This is a girl of 16 years; her life has been ruined"

A young boy in Umuahia retorted:

If our parents don't give us information why can't the school teach this to let us know more of the problems we may likely face if we start to have fun too early in life. Government should also do proper campaign for young boys and girls to know and be aware.

The spread of sexually transmitted infections and increase in the number of young girls with unplanned pregnancies is of general concern to adolescents. Many are also worried about changes in the percep- tion of what is right and wrong among adolescents and the increasing difficulties of staying out of trouble. Many schools do not have trained guidance counselors to teach adolescents basic things such as courtship and relationships.

\section{Summary and conclusions}

Adolescents who are sexually active face several risks, among which are: contracting HIV and other STIs, unwanted pregnancy, unsafe abortions, highrisk deliveries, reduced educational opportunities and poor economic outcomes. Early childbearing is often strongly associated with a young woman's failure to complete her education thus limiting her future job prospects and her own and children's economic well-being. Improving adolescent reproductive health and reducing teenage pregnancy are essential ingredients of policy measures. Helping youths to make a healthy transition is therefore critical to the development and prosperity of the future.

Premarital sexual intercourse, increasingly rampant among adolescents, is fast becoming the acceptable norm rather than a traditionally condemnable act. An insignificant number of adolescents with secondary, primary schooling or below consider culture and taboo a constraining factor in discussing sex. Adolescents are not deriving enough care and concern from the community because of the rigid traditional norms on sexuality issues, especially for adolescents.

The study also showed that parents' primary responsibility of educating their children is often hampered by cultural taboos which make it difficult to discuss sexual matters. Such matters relating to sex and sexuality are usually shrouded in secrecy. Most adolescents now rely on radio and television as sources of information for sexuality and family life education which may not in some respect serve as good sources of information for them. Parents are in the best position to influence the lives of their children right from infancy. Some adolescents emphasized that parents should educate their children about growth related challenges associated with adolescence and what the society expects of them. Unfortunately, some parents are themselves not knowledgeable enough and some do not appreciate the importance and value of educating their adolescent children in reproductive health issues. Some parents are also very shy to discuss sexual matters with children because they have been taught that culture forbids children from being prematurely exposed to sexual matters.

Poorly informed peers are sources of information for adolescents. Peer interaction influences the sexual behaviour of adolescents, governed as it 
were, by what their friends say and do. They also generally tend to prefer discussing the subject with their peers who are also usually misinformed about sexuality issues, resulting in a situation of the "blind leading the blind".

In conclusion, it can be deduced from the study that culture is a major barrier to communication between parents and children. Sexual issues are seen as taboo which should not be discussed with very young people. Programmes to enlighten the communities, parents and adolescents should ensure that stakeholders understand the current needs of young people, the need to interact more intimately with adolescents and spend quality time to listen to their views and concerns.

The country's cultural heterogeneity and other traditions perpetuate rules and norms that affect the perceptions of parents, teachers and others and therefore serve as catalysts against the successful implementation of sexuality education in the country. Young women are socialized to be submissive and avoid discussions on sex thereby constraining them to refuse sex or insist on use of condom, hence, adolescents need to be provided factual and accurate sexual information about the dimensions of sexual knowledge that will enable them understand and clarify their personal values, improve their sexual knowledge and sexual decision-making and promote their knowledge about how all these interact with socio-cultural and religious factors to affect personal well-being.

Most adolescents and their parents are predominantly Christians or Muslims hence adolescent reproductive health issues discussed in faith-based settings are regarded by believers as divine messages. Faith-based organizations are to impart moral education and fill the gap abdicated by the school and the family. However, there is a need to harmonize the teachings of all these to ensure that young people are not confused.

The school has an important role to play in promoting social change since it is there that adolescents pick up most information on sexual matters, eventually form habits and struggle with the influence of peer groups, hence there is need for the school to collaborate with the home in bringing positive change to adolescent sexual health

The summations of this study point to the critical role of the home, school and the society in shaping the adolescent reproductive health behavior in Nigeria. The home as the primary agency of socialization needs to be reenergized and empowered through public enlightenment campaigns and educational programmes about its responsibilities in making sure that their children imbibe moral values that can persuade them to conform to standards, rules and regulations about their (children's) reproductive health. Nigerian adolescents are frequently in doubt as to whether a certain course of action is good or bad, due to lack of appropriate information from the adult society. Hence the adolescents' attitude towards their reproductive health status, especially in this era of distractive tendencies, is simply that, the school needs to develop methodologies and the parents need to find the appropriate time to "sit them down" to teach and give them factual and vital information about adolescent reproductive health issues. This is a challenge for all stakeholders that also requires further investigation that can throw more light into how the adolescents can learn the right moral values, internalize them, live and abide by them in order to promote positive adolescent reproductive health outcomes.

\section{Acknowledgement}

We wish to express our appreciation to the Human Resources Development Centre (HRDC), Lagos, Nigeria for permission to use part of the data collected in the study: Adolescent Sexual and Reproductive Health in Nigeria: Behavioural Patterns and Needs under the auspices of the African Social Research Programme (ASRP), Africa Division, United Nations Population Fund (UNFPA). All the details and interpretations contained in this paper remain the responsibility of the authors and in no way commit HRDC and UNFPA.

\section{References}

Adepoju, Adunola, (200I): Perspectives on Population Education in Nigeria, Lagos: Concept Publications Adepoju, Adunola, (2005): Sexuality and Life Skills Education. London: PenPress Publishers

Adepoju, A., P.O. Ogunjuyigbe and Adunola Adepoju. Adolescent Sexual and Reproductive Health in Nigeria: Behavioural Patterns and Needs, 2006, iUniverse, New York, USA.

Adeokun L.A., O.L. Ricketts, A.J. Ajuwon and O.A. Ladipo (2009): Sexual and Reproductive Health Knowledge, Behaviour and Education Needs of In-School Adolescents in Northern Nigeria, African Journal of Reptroductive Health 13[4]:3749

Akingba, J. B. (2002): Abortion mortality and other health problems in Nigeria. Nigeria Medical Journal, I(4), 465 - 47I

Akanle, F.F. (2007): Reasons for increase in Adolescent Sexual Activities in Nigeria. Pakistan Journal of Social Sciences 4(5): 647-653.

Alo, O.A. and Akinde, I.S. (2010): Premarital Sexual Activities in an Urban Society of Southwest Nigeria. www.ea-journal .com vol.2, No.I 
Bolaji, S.L. ( 1 984): Yoruba Living Heritage. Ibadan: Omoleye Publishing Company.

Esere, M.O. (2008): Effect of sex education programme on at-risk sexual behaviour of school-going adolescents in llorin, Nigeria. African Health Sciences 2008: 8(2): I20-125

Feyisetan, B. J and Pebley, A. R. (1 989) Premarital sexuality in urban Nigeria. Studies in Family Planning. Vol. 20, No. 6

Isiugo-Abanihe, I. M. and U. C. Isiugo-Abanihe (2007) Adolescent Sexuality and Reproductive Health in two Oil Producing Communities in Imo and Rivers States, Nigeria. African Population Studies, 22 (2): 46-76

James, G. and Isuigo-Abanihe, U.C. 2010. Adolescents' Reproductive Motivations and Family Size Preferences in North-Western Nigeria. Asian Journal of Medical Sciences, 2(5): 218-226.

Miangotar Y. and T. LeGrand (20I2): Association between Age at First Sexual Relation and Some Indicators of Sexual Behaviour among Adolescents. African Journal of Reproductive Health (Special Edition); 16[2]: 173-188

Mitike, Berhane, and Lindtjørn (2008): Traditional values of virginity and sexual behaviour in rural Ethiopian youth: results from a cross-sectional study. BMC Public Health, 8:9

Meekers D. (1994): Sexual initiation and premarital childbearing in sub-Saharan Africa, Population Studies. 48(I): 47-64

National Population Commission (NPC) [Nigeria] and ORC Macro. 2004. Nigeria Demographic and Health Survey 2003. Abuja, Nigeria: National Population Commission and ORC Macro.

National Population Commission (NPC) [Nigeria] and ICF Macro 2009. Nigeria Demographic and Health Survey 2008. Abuja, Nigeria: National Population Commission and ICF Macro.

Nugent, R. (2006): Youth in a Global World, Bridge, PRB

Okore, A.O. (1987): "Fertility determinants among the Igbo in Eastern Nigeria" In The Cultural Roots of African Fertility Regime: proceedings of the Ife Conference, 25 February - I March, 1987 (eds) A. Ebigbola and E. Van de Walle, lle-lfe: Department of Demography and Social Statistics, Obafemi Awolowo University and Philadelphia Population Studies Center, University of Pennsylvania, pp. 295-304.

Slap G.B., L. Lot, B. Huang, C.A.Daniyam, T.M. Zink, and P.A. Succop (2003): Sexual behaviour of adolescents in Nigeria: cross sectional survey of secondary school students. BMJ. ;326(7379): I5.

Tunau K.A., A. N. Adamu I, M. A. Hassan, Y. Ahmed, B. A. Ekele (20I2): Age at menarche among school girls in Sokoto, Northern Nigeria. Annals of African Medicine Vol. I I, No. 2

Uchendu, V.C. (1965): The lgbo of Southeast Nigeria. New York: Holt, Rinehart and Winston.

Walker, Judith-Ann (20I2): Early Marriage in Africa Trends, Harmful Effects and Interventions African Journal of Reproductive Health (Special Edition); I6[2]: 23I-240

World Health Organization. 20I I. The sexual and reproductive health of young adolescents in developing countries: Reviewing the evidence, identifying research gaps, and moving the agenda. Report of a WHO technical consultation, Geneva, 4-5 November 2010.

World Health Organization/UNFPA 2006. Pregnant Adolescents. Geneva: WHO, 2006. 